\title{
Applying Narrative Theories in the Design of Public-cause Posters: Process and Educational Implications
}

\author{
Chao-Ming Yang \\ Department of Visual Communication Design \\ Ming Chi University of Technology, New Taipei City, Taiwan \\ Tzu-Fan Hsu \\ Department of Commercial Design \\ Chung Yuan Christian University, Taoyuan City, Taiwan;
}

\begin{abstract}
Narration refers to the act by which a narrator conveys a message to his or her audience through storytelling. It can facilitate the delivery of a message that is presented in visual forms and add an emotional appeal to the work. In this study, literature on narration was reviewed to develop a narrative design model for public-cause posters, and the model was used to prepare posters on the basis of two issues for model verification. From the poster creation process, we found that narrative theories can be integrated into design education to foster creative thinking among students and facilitate their topic exploration. Thus, this model provides a concrete systematic framework for the design of narrative-based public-cause posters. In summary, narrative theories can be incorporated into visual communication design education to inspire students and inform their elucidation of social and cultural milieus in their works.
\end{abstract}

Keywords: Narrative theory, Narrative design, Public-cause posters, Visual communication design.

\section{INTRODUCTION}

Existing narrative theories have broad applications. They involve the communicability and credibility of messages and linguistic and semiotic aspects. Therefore, these theories have been extensively studied (Smith, 1980). Narration refers to the act by which a narrator conveys a message to his or her audience through storytelling (Louchart \& Aylett, 2004a). People are often drawn to stories. However, storytelling is not a simple task; it requires sophisticated communication skills to engage readers or the audience in the emotional or intellectual aspects of plots. Moreover, people interpret stories they read or hear varyingly, usually on the basis of their life experiences (Babb, 2002).

Narratology was first proposed by Tzvetan Todorov in 1966 and did not receive wide academic attention until 1985 (Bal, 2009). Narrative methods originated from literature and semiology; through considerable scholarly research, they evolved into a set of theories (Aylett \& Louchart, 2003) that underpin numerous studies into the depths of people's life experiences and inner selves (McAdams, 2006). Early narratology research focused on mythological stories and the works of narrative fiction. However, since the advent of structuralist approaches, narratology has extended to other forms of human creativity, art, and entertainment, including theater, film, crosstalk comedy, installation art, architecture, documentary, and arts and design; thus, narrative components have been increasingly incorporated into numerous types of design work (Louchart \& Aylett, 2004b). 
Narratology is a new concept in design practices and has been extensively studied. However, no comprehensive design methodology based on narratology has been developed because this discipline has been discussed predominantly in theoretical terms, underlining the need to create narratology-based designs. Moreover, our long-term participation in design exhibitions across Asia and experience in teaching visual design suggest that the design ideas conceived by design students is nearing an impasse and the perpetual development of design-related software has caused students to focus more on the "effect" than on the "substance" of their works. Many contemporary works of digital media and graphic design lack originality and share virtually the same thematic components because the growing convenience of technology prompts designers to, knowingly or unknowingly, emphasize visual effects more than they do substance. Thus, this study integrated narrative theories with the design principles of visual communication to develop a methodology for creating posters. This methodology is expected to inform design practice and education.

\section{From Narratology to Narrative Design}

Since it was formally proposed by Todorov (1969) in Grammaire du Décaméron, narratology has been discussed in Western literary communities (Herman, 2007). It was dominated by structuralist approaches in its beginnings and did not attract global attention until recently. Structuralist narratology is dedicated to shifting attention from the external to internal structure of a narrative text and elucidating the internal structure of the text and the relationships between all narrative components in a scientific systematic manner (Fludernik, 2007). The origin of narration can be traced back to ancient times, when humans created myths and used symbols as a means of description and communication. Although early narratological approaches were applied to narrating myths and folktales, all visible and intelligible symbols or objects readily associable with specific meanings may form parts of a narrative. As such, narration provides a fundamental means of exploring a society and reflecting on the world around us and our own lives (Bruner, 2004).

Narratology (as it is called by Western philosophers and scholars) is the fruit of human endeavors to analyze the structures of stories of different genres and the formats and functions of narration (Bal, 2009). Specifically, it reproduces stories, events, and phenomena in a semiotic manner (Herman, 2007). Recently formulated narrative theories have had implications for arts and design; narrative design methods for visual communication design are based on iconology (Yang, 2009). A typical narrative comprises a story, discourse, and narration. These components are instrumental in organizing a series of related events into a coherent narrative whose content (which is presented) constitutes the text of a story (Liu, 2008). In summary, a story presents events in a narrative framework and in a dramatic fashion, narrative discourse is an account of related events, and narration refers to the act of telling a story.

Narrative text underlies narrative theories. It can be presented in the forms of language, imagery, voice, architecture, or mixed media (Bal, 2009). Therefore, cultural products with narrative components warrant academic investigation (Fludernik, 2007). The human memory narratively captures information (particularly when it is presented in a disorganized or ambiguous manner), allowing a person to confirm and recall it readily whenever necessary. As such, crafting a tale narratively enables a person to regain his or her memories, establish cause-effect relationships for a disordered arrangement of ideas, and portray a character in stark contrast to popular perception (Liu, 2008). According to these arguments, this study conceive narration to be a method for storytelling, and arguing that a design work is characteristically a story in which the designer can narrate vividly what he or she has heard, learned, or experienced. 


\section{Constructing a Model of Narrative Design}

Claude Bremond (1929-1973) was a renowned French scholar of narrative theories. He proposed les possibles narratifs on the basis of Vladimir Propp's (1895-1970) theory regarding narrative characters and their functions to illustrate the possible relationships between the characters and plot development. In Bremond's view, characters' functions are logically related to plots; such relationships may lead to narrative sequences (Pavel, 1980), which are then combined to form a complete story (Zhao, 2007). Premised on logic, narrative sequences constitute the underlying structure of a narrative work and can be divided into elementary and complex sequences (Polkinghorne, 1989). The elementary sequence underlies Bremond's narrative theory. Thus, this study used the elementary sequence as the theoretical framework for a design work. The elementary sequence describes the development of an event in terms of its potentiality, process, and attainment, as depicted in Figure 1.

1. A1-Potentiality: A situation in which a character acts (functions) according to what the character is about to do or what is about to happen, leading to changes in plot development.

2. A2-Process: A situation in which a character acts (functions) according to an ongoing action or event, leading to a possible actualization of the changes in the plot development.

3. A3-Attainment: A situation in which a character acts (functions) according to attainment of outcomes, which closes the story.

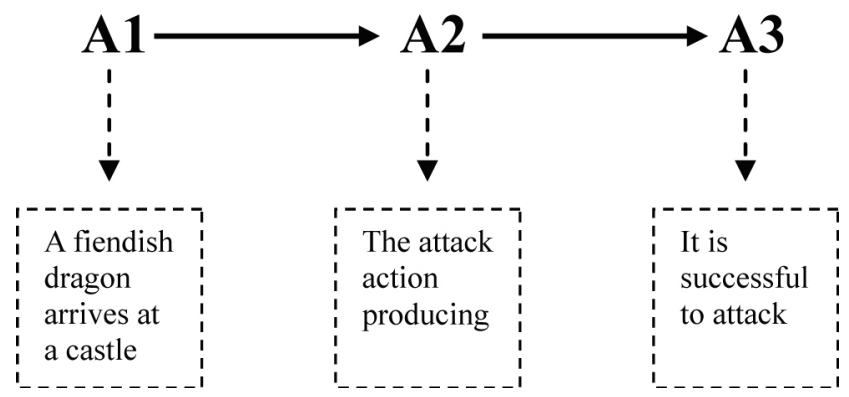

Figure 1. Bremond's elementary sequence of narration

"Reason for action" (A4) can be added to the elementary sequence to complement a narrative design. Therefore, A4 was used in this study as the relationship between A1 and A2 to account for a given action performed by a character (Figure 2). Take for example a fiendish dragon in the legend of King Arthur. The cause-effect relationships within the tale can be elucidated with the addition of A4: (A1) When a fiendish dragon arrives at a castle, (A4) it finds the residents of the castle, salivates at the thought of eating them, (A2) attacks them, and (A3) destroys the castle. As such, A4 provides the rationale for public-cause posters, which are intended to raise public awareness of the consequences of human desires such as self-interest. To ensure the comprehension of the subsequent poster analysis regarding public issues, A4 was defined as "desire." Thus, a poster concerning environmental disruption can be presented in such a textual narration sequence: Obsessed with the convenience brought about by electricity (desire), humans use electrical appliances excessively, putting the world at risk of destruction. Such a sequence of narration provides the basis for the rendition of a poster narrative into intelligible symbols. Thus, this process was defined in this study as the sequence of narrative statement, as illustrated by Figure 3. 


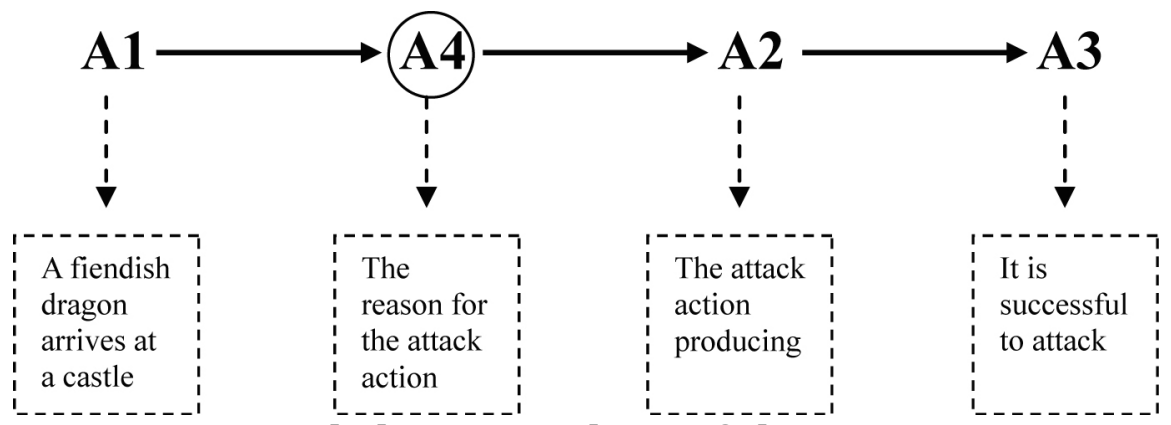

Figure 2. Extended narrative logic of elementary sequence

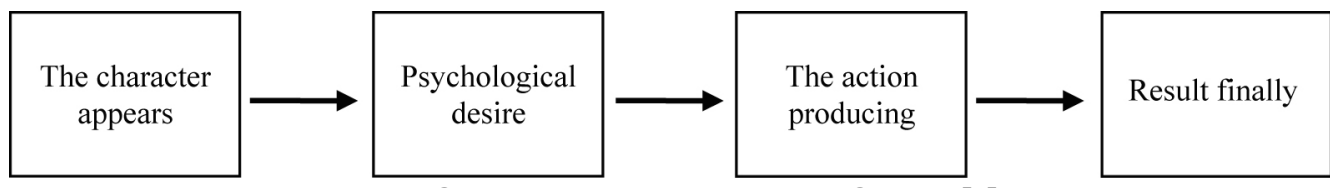

Figure 3. Sequence of narrative statement for public-cause posters

Yang (1998) divided the production of creative works that are based on cultural codes into three dimensions: strategic, meaningful, and technical. The present study applied this method to poster design, such that the strategic dimension is the overarching theme of a poster, the meaningful dimension is the implication or meaning of each symbol in the poster, and the technical dimension is how the poster is displayed. Accordingly, the sequence of narrative statement can be compared with the strategic dimension because it describes the purpose of a poster. On the basis of the aforementioned theoretical premises, this study proposed a model for the narrative design of public-cause posters, as shown in Figure 4:

1. Dimension of narrative statement: Involves describing in cause-effect terms the issue illustrated in a public-cause poster.

2. Dimension of symbolic instantiation: Involves rendering all the components of a narrative statement, on the basis of their respective meanings, into concrete ideas.

3. Dimension of technique: Involves techniques used in poster display.

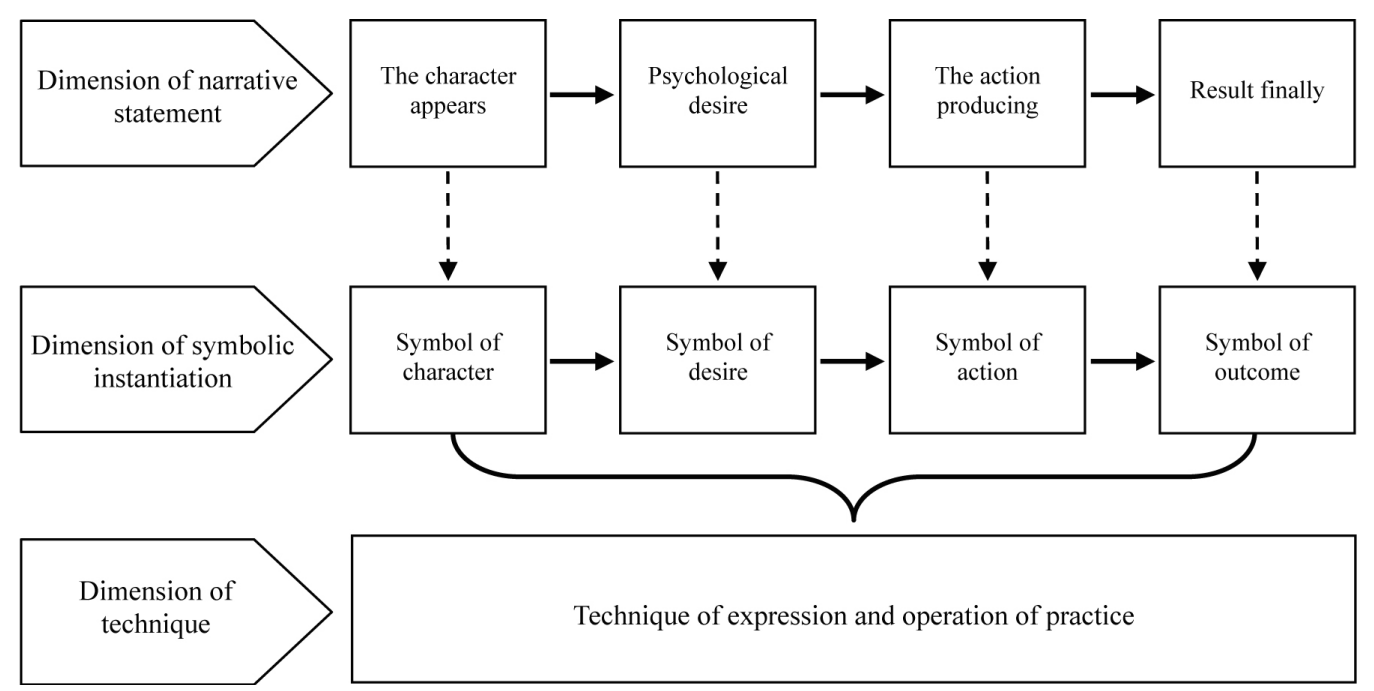

Figure 4. Narrative design model for public-cause posters 


\section{Verification: Designing Narrative Public-cause Posters Overview and Procedure}

First, factual stories from the media and other sources were collected and subsequently integrated into the dimension of narrative statement. Next, narrative statements were mined for keywords, which were converted into the dimension of symbolic instantiation. A poster was subsequently sketched in line with the physical characteristics of symbolic images. Finally, in the dimension of technique, the designer used techniques of his or her choice to complete the poster. The procedure for producing a narrative public-cause poster is detailed as follows:

1. Basing the theme on an issue concerning society, environment, human rights, peace, or related topics.

2. Using news articles as material for writing a narrative.

3. Integrating news stories into the sequence of narrative statement.

4. Rendering the meanings of narrative statements into intelligible symbolic images.

5. Producing a sketch in line with the physical characteristics of symbolic images.

6. Employing proper techniques to depict the narrative of a poster.

\section{Issues Covered in Posters}

\section{Sample A: Abstinence from illegal substances}

Drug-related crimes are frequently reported by media outlets in Taiwan. Such news stories suggest that cases of drug addiction at the expense of one's own life are increasing in number and that more young adults take illegal substances than do any other age group. Thus, the narrative of the first public-cause poster was based on a news article (from a Taiwanese media outlet) that describes a physician's reflections on treating two teenage drug users (Table 1).

\section{Table 1: Interview transcript in a news article used for creating a poster concerning avoiding illegal substances}

\section{A Girl Crying Over Her Drug Use}

I had two drug users in my recent outpatient clinic sessions, a young boy and girl. They used ketamine and amphetamine. The girl reported frequent urination, and I assumed this was a symptom of bladder inflammation. The boy reported auditory hallucinations and persecutory delusions. I bent over backward to ensure that they and their family members have realized the dangers of taking substances. The girl wept, saying she had been encouraged by her friends to try them but didn't know the grave consequences of doing drugs. Seeing her sobbing in regret had me think over various issues. Drug addiction is a serious problem worldwide. Taking substances undermines one's health and can cause irreversible conditions (e.g., having to wear diapers or developing mental illnesses) that last a lifetime. Drug users are also prone to distraction, auditory hallucinations, delusions, and violence, and are therefore highly likely to cause traffic accidents or harm others. Moreover, dealing in substances provides many crime syndicates with an essential means of holding people in their grip and bribing the authorities. Thus, more topics on substances, especially those popular among teenagers (such as ketamine, ecstasy, and amphetamine), should be covered in health education at school. Statistics show that the number of ketamine abusers in Taiwan has risen over forty-fold in the past decade; most drug abusers are children under 19. 
A poster based on this reported news content was prepared on the basis of the dimensions of narrative statement, symbolic instantiation, and technique:

(1) Dimension of narrative statement: The news article was summarized on the basis of the four components of a narrative (character, desire, action, and outcome) into an outline for the narrative of a related public-cause poster: More and more young adults, at their friends' urging and out of curiosity, take ketamine, ending in poor health, mental disorders, and even in tombs.

(2) Dimension of symbolic instantiation: Next, all the four components of the narrative outline were rendered in accordance with the researcher's knowledge into their corresponding symbolic textual images (Table 2). To associate the narrative with concrete objects, several visual images (symbols) related to substance abuse were retrieved from the Internet using keywords extracted from the dimension of symbolic instantiation of the narrative. These images were merged on a drawing according to their respective features to form a poster sketch (Table 3).

(3) Dimension of technique: The poster was presented through photographs because concrete images contribute to the association of posters with the issues they are intended to promote. Table 4 tabulates the design concept and illustrates the poster.

Table 2: Symbolic textual images of the narrative of a public-cause poster concerning avoiding illegal substances

\begin{tabular}{|c|c|c|c|c|c|c|c|c|}
\hline \multirow{2}{*}{$\begin{array}{l}\text { Dimension of } \\
\text { narrative } \\
\text { statement }\end{array}$} & $\mathbf{a}$ & $\begin{array}{c}\text { The } \\
\text { character } \\
\text { appears }\end{array}$ & b & $\begin{array}{l}\text { Psychological } \\
\text { desire }\end{array}$ & c & $\begin{array}{l}\text { The action } \\
\text { producing }\end{array}$ & d & Result finally \\
\hline & \multicolumn{2}{|c|}{$\begin{array}{c}\text { more and more } \\
\text { teenagers }\end{array}$} & \multicolumn{2}{|c|}{$\begin{array}{l}\text { instigated by the } \\
\text { bad friend, } \\
\text { personal curiosity }\end{array}$} & \multicolumn{2}{|c|}{$\begin{array}{c}\text { sucking the drug } \\
\text { of ketamine which } \\
\text { endanger life and } \\
\text { health }\end{array}$} & \multicolumn{2}{|c|}{$\begin{array}{l}\text { cause the body } \\
\text { function to be } \\
\text { damaged, and } \\
\text { spirit is confused } \\
\text { even beath }\end{array}$} \\
\hline \multicolumn{9}{|c|}{$\downarrow$} \\
\hline \multirow[b]{2}{*}{$\begin{array}{l}\text { Dimension of } \\
\text { symbolic } \\
\text { instantiation }\end{array}$} & $\mathbf{a}$ & $\begin{array}{l}\text { Symbol of } \\
\text { character }\end{array}$ & $\mathbf{b}$ & $\begin{array}{l}\text { Symbol of } \\
\text { desire }\end{array}$ & c & $\begin{array}{c}\text { Symbol of } \\
\text { action }\end{array}$ & d & $\begin{array}{l}\text { Symbol of } \\
\text { outcome }\end{array}$ \\
\hline & \multicolumn{2}{|c|}{$\begin{array}{l}\text { Teenagers (young } \\
\text { boys or young } \\
\text { girls) }\end{array}$} & \multicolumn{2}{|c|}{$\begin{array}{l}\text { temptation, to rise } \\
\text { to the bait, bad } \\
\text { fridents, curiosity } \\
\text { killed the cat }\end{array}$} & \multicolumn{2}{|c|}{$\begin{array}{l}\text { powder, to suck, } \\
\text { self-annihilation, } \\
\text { scorpion, spider, } \\
\text { centipede, snake }\end{array}$} & \multicolumn{2}{|c|}{$\begin{array}{l}\text { skull, phonism, } \\
\text { persecutory } \\
\text { delusion, violent } \\
\text { tendencies, } \\
\text { looking feeling } \\
\text { sickly }\end{array}$} \\
\hline
\end{tabular}


Table 3: Sketch of a public-cause poster concerning avoiding illegal substances

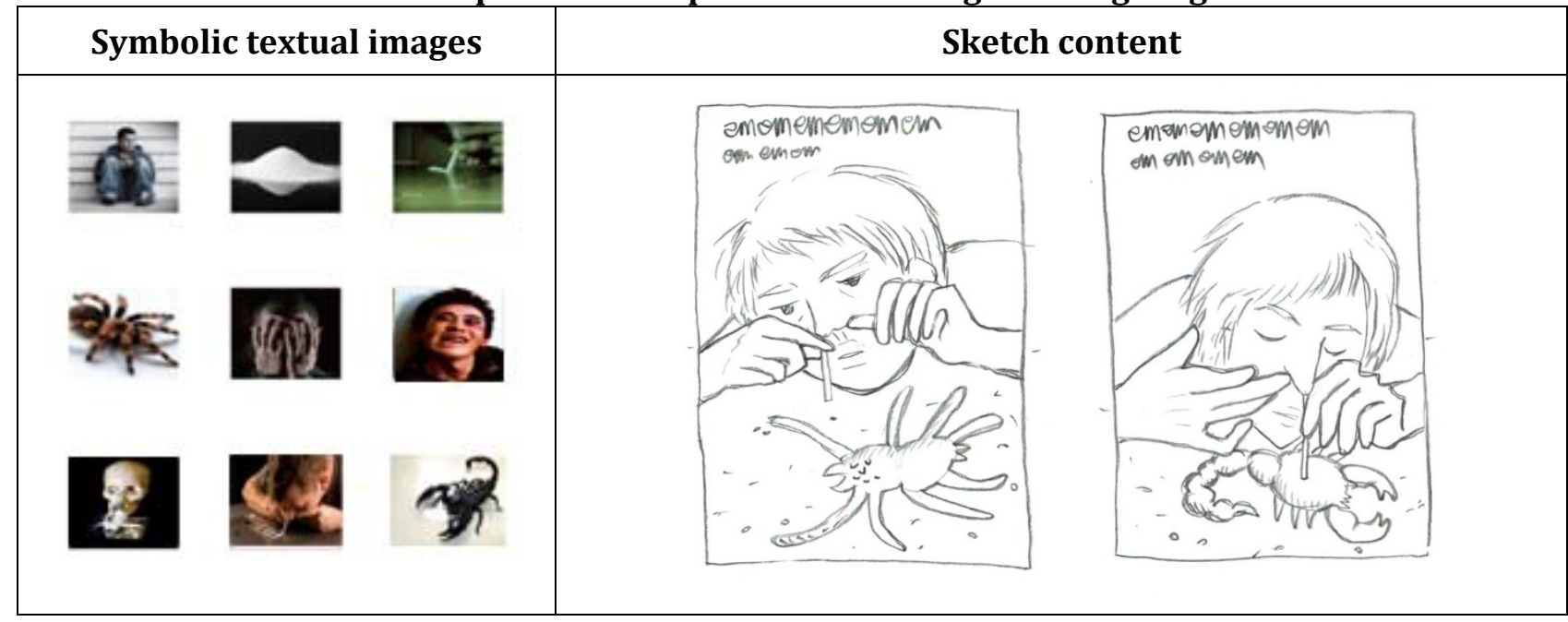

Table 4: Design concept and image content of a public-cause poster concerning avoiding illegal substances

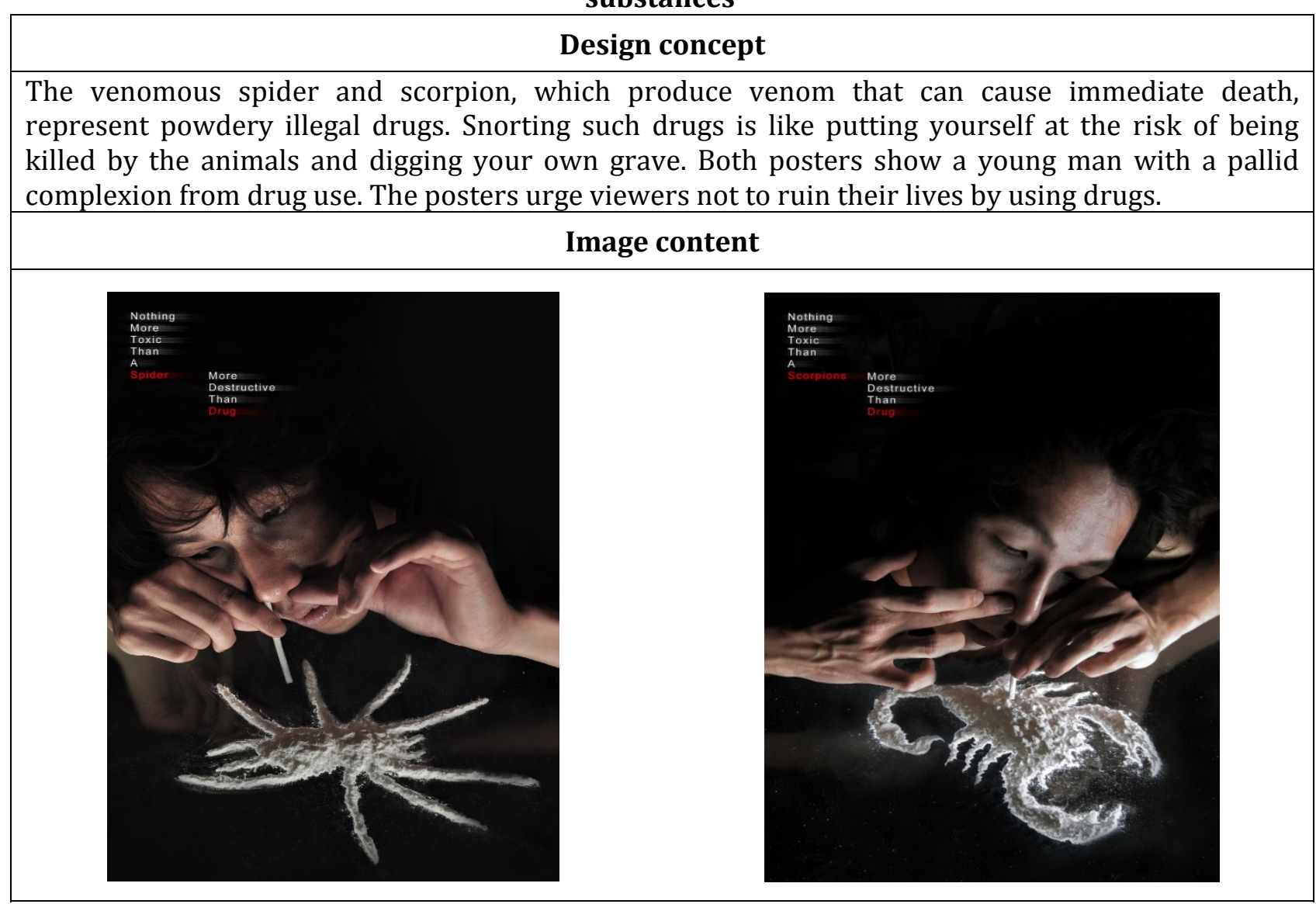

\section{Sample B: Nuclear disaster}

Public efforts to have nuclear power plants decommissioned have intensified in Asia, Europe, and North America. Although nuclear power plants generate substantial economic benefits, their potential threat is responsible for the growing public demand for their decommissioning. The Fukushima Daiichi nuclear disaster illustrated to the world that the dangers and fears associated with nuclear power are beyond human comprehension. Because of the increasing 
public attention to nuclear disasters, we also prepared a poster regarding this issue for this study. The narrative of this poster was based on a news article (from a Taiwanese media outlet) that describes a Japanese nongovernmental organization's (NGO) publication that was published to improve public understanding of nuclear power plants and nuclear accidents and how to respond to them (Table 5).

\section{Table 5: News article content used for creating a poster concerning the dangers of nuclear power}

\section{Japanese NGO: Ten Lessons from the Fukushima Daiichi Nuclear Disaster}

Five years ago today, a massive magnitude 9.0 earthquake struck northeastern Japan, triggering tsunami waves that claimed millions of lives and caused three reactors in the Fukushima Daiichi Nuclear Power Plant complex to explode and melt down. The incident destroyed at least 40,000 homes in the region, with around 230,000 residents still left displaced. Adding to this diaster was the storage of up to 22 million cubic meters of nuclearcontaminated soil. The Japanese government has earmarked 1.1 trillion JPY to build temporary storage facilities in the towns of Futaba and Okuma in Fukusima and transfer the soil to the facilities. The Japan Civil Society Organization Coalition for the 2015 World Conference on Disaster Risk Prevention, an NGO in Japan, has published a booklet that provides 10 lessons concerning the nuclear disaster to improve public understanding of nuclear power plants and nuclear accidents and how to respond to them: (1) Do not be fooled by the "Nuclear Power is Safe" propaganda; (2) During an emergency, the basic premise is to run away; (3) Access to information and leaving records is vital; (4) People aff $\neg$ ected by the disaster have the right to a comprehensive health survey and disclosure of information; (5) To ensure food safety and to protect agriculture, forestry, and fishery industries,citizens must participate in measurement. Information disclosure is also vital; (6) Complete decontamination is impossible; (7) The accident cannot be brought to a conclusion unless workers are given better treatment and healthcare; (8) Rebuilding the daily lives and community of those a $\neg f f e c t e d$ is essential; (9) Calling for the participation of those a $\neg f f e c t e d$ by the disaster in the enactment and implementation of laws that are designed to protect them; (10) Taxpayers are being made to bear the compensation costs.

A poster that was based on this news article content was prepared on the basis of the dimensions of narrative statement, symbolic instantiation, and technique:

(1) Dimension of narrative statement: The news article was summarized on the basis of the four components of a narrative (character, desire, action, and outcome) into an outline for the narrative of a related public-cause poster: People rely excessively on nuclear power; they will face the irremediable consequences of this undue reliance unless they cease using it.

(2) Dimension of symbolic instantiation: Next, all the four components of the narrative outline were rendered in accordance with the researcher's knowledge into their corresponding symbolic textual images (Table 6). To associate the narrative with concrete objects, several visual images related to nuclear disasters were retrieved from the Internet using keywords extracted from the dimension of symbolic instantiation of the narrative. 
These images were merged on a drawing according to their respective features to form a poster sketch (Table 7).

(3) Dimension of technique: The poster was presented through photographs, because concrete images contribute to the association of posters with the issues they are intended to promote. Table 8tabulates the design concept and image content of the poster.

Table 6: Symbolic textual images of the narrative of a public-cause poster concerning nuclear disasters

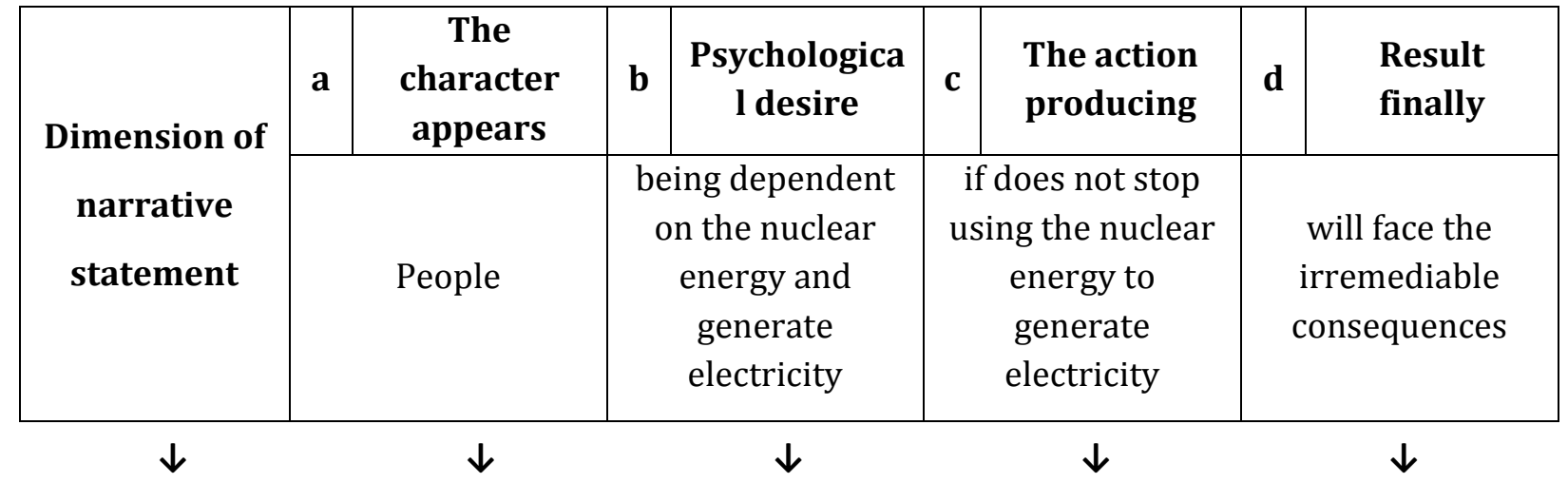

\begin{tabular}{|c|c|c|c|c|c|c|c|c|}
\hline \multirow[b]{2}{*}{$\begin{array}{l}\text { Dimension of } \\
\text { symbolic } \\
\text { instantiation }\end{array}$} & $\mathbf{a}$ & $\begin{array}{l}\text { Symbol of } \\
\text { character }\end{array}$ & $\mathbf{b}$ & $\begin{array}{l}\text { Symbol of } \\
\text { desire }\end{array}$ & c & $\begin{array}{c}\text { Symbol of } \\
\text { action }\end{array}$ & d & $\begin{array}{l}\text { Symbol of } \\
\text { outcome }\end{array}$ \\
\hline & & $\begin{array}{l}\text { owd of people } \\
\text { image }\end{array}$ & & $\begin{array}{l}\text { luclear power } \\
\text { iont, a sign of } \\
\text { radiationg } \\
\text { consuming } \\
\text { electronic } \\
\text { product, wall } \\
\text { socket }\end{array}$ & & $\begin{array}{l}\text { a switching } \\
\text { mechanism, } \\
\text { rohibiting sign }\end{array}$ & & $\begin{array}{l}\text { ath, radiation } \\
\text { rning symbol, } \\
\text { ioactive rays, } \\
\text { ust-eaten, a } \\
\text { ible explosion }\end{array}$ \\
\hline
\end{tabular}

Table 7: Sketch of a public-cause poster concerning nuclear disasters

\begin{tabular}{|l|l|l|c|}
\hline \multicolumn{2}{|c|}{ Symbolic textual images } & Sketch content \\
\hline & & \\
\hline
\end{tabular}


Table 8: Design concept and image content of a public-cause poster concerning nuclear disasters

Design concept
The image of a flashlight bearing a warning symbol of nuclear power production suggests that even
using a trivial amount of electricity, such as equivalent to what a flashlight needs can do irreversible
harm to the environment, let alone when the power is obtained from nuclear energy. The overlaid
text of “STOP" in the middle serves to highlight a pressing need to cease using nuclear power. The
title of the Chinese caption on the posters reads 相煎核太急 (xiang jian he tai ji) or "why are we so
eager to use nuclear energy?". The word he ("nuclear") is used to make a pun as the pronounciation
of the word for why (he) in the Chinese saying xiang jiang he tai ji or "why are we so eager to harm
each other?" is the same. Accordingly, the caption points to an irony that humans have invented a
technology that may eventually lead them to their destruction.
Image content

\section{CONCLUSIONS AND SUGGESTIONS}

Narration has been practiced throughout human history to explore the world and enable people to view themselves in the context of the societies in which they live. It has been around since our ancestors created myths and communicated through graphical and textual means (Fludernik, 2007). Accordingly, narration has been part of human culture throughout the ages and across the world (Barthes \& Duisit, 1975). Moreover, in terms of the evolution of human history, not only narration but also visual communication designs have existed ever since the dawn of humanity. Visual communication design involves combining words and visual arts to create an artistic, symbolic, and informative visual product that can improve cross-cultural understanding. As such, this creative process may serve to transmit messages that transcend national, historical, and cultural boundaries.

Some designers may be skeptical of whether narration is a necessary skill for making visual communication designs. However, this study found that narration can facilitate the delivery of the message of a visual communication design and adds an emotional appeal to the work. Moreover, the focus of design education has shifted from "functionality" (the focal point of the Bauhaus style) to "emotionality," underlining the need for designers to impart to their works an emotional dimension and for researchers and educators to respond to the implications of growing interest in "emotional design" and "narrative design." In terms of its application, 
visual communication is widely regarded as a vehicle for cultural values; it not only serves commercial purposes but also facilitates the creation of social and cultural constructs. Given these arguments, narrative theories can be incorporated into visual communication design education to inspire students and inform their elucidation of social and cultural milieus in their works.

This study reviewed literature on narration to develop a narrative design model for public-cause posters and used the model to prepare such posters on the basis of two issues. From the poster creation process, we found that narrative theories can be integrated into design education to foster creative thinking among students and facilitate their topic exploration. The narrative design model for public-cause posters comprises a series of interlocking dimensions: narrative statement, symbolic instantiation, and technique. The components of a news article are first summarized in sequential order (character $\rightarrow$ desire $\rightarrow$ action $\rightarrow$ outcome) in the dimension of narrative statement, furnished with symbolic textual images in the dimension of symbolic instantiation, and presented in the form of posters in the dimension of technique. This model provides a concrete systematic framework for the design of narrative-based public-cause posters.

\section{ACKNOWLEDGEMENT}

The authors gratefully acknowledge the support for this research provided by the Ministry of Science and Technology of Taiwan under Grants No. MOST 105-2410-H-131-004-. Furthermore, the authors also thank Mr. You-Sian Chen for collecting images and creating posters in this study.

\section{References}

Aylett, R., \& Louchart, S. (2003). Towards a narrative theory of virtual reality. Virtual Reality, 7(1), pp. 2-9.

Babb G. (2002). Where the bodies are buried: Cartesian dispositions in narrative theories of character. Narrative, 10(3), pp. 195-221.

Bal, M. (2009). Narratology: Introduction to the theory of narrative. Toronto: University of Toronto Press.

Bruner, J. (2004). Life as narrative. Social Research, 71(3), pp. 691-710.

Fludernik, M. (2007). Histories of narrative theory (II): From structuralism to the present. In: A companion to narrative theory (Chapter 2), Phelan, J. \& Rabinowitz, P. J. (Eds.), pp. 36-59, New Jersey: John Wiley \& Sons.

Herman, D. (2007). Histories of narrative theory (I): A genealogy of early developments. In: A companion to narrative theory (Chapter 1), Phelan, J. \& Rabinowitz, P. J. (Eds.), pp. 19-35, New Jersey: John Wiley \& Sons.

Louchart, S., \& Aylett, R. (2004a). Narrative theory and emergent interactive narrative. International Journal of Continuing Engineering Education and Lifelong Learning, 14(6), pp. 506-518.

Louchart, S., \& Aylett, R. (2004b). The emergent narrative theoretical investigation. In: The 2004 Conference on Narrative and Interactive Learning Environments (pp. 21-28).

McAdams, D. P. (2006). The role of narrative in personality psychology today. Narrative Inquiry, 16(1), pp. 11-18.

Pavel, T. G. (1980). Narrative domains. Poetics Today, 1(4), 105-114.

Polkinghorne, D. E. (1989). Narrative knowing and the human sciences. American Journal of Sociology, 95 (1), pp. 258-260.

Smith, B. H. (1980). Narrative versions, narrative theories. Critical Inquiry, 7(1), pp. 213-236.

Yang, Y. F. (2009). A Discourse of Narrative Design in Architecture Aesthetics. Journal of Architecture, 69, pp.155-168. [publish in Chinese] 